\title{
Successful treatment of severe respiratory papillomatosis with intravenous cidofovir and interferon $\alpha-2 b$
}

\author{
C. Armbruster*, A. Kreuzer\#, H. Vorbach*, M. Huber", C. Armbruster ${ }^{+}$
}

Successful treatment of severe respiratory papillomatosis with intravenous cidofovir and interferon $a-2 b$. C. Armbruster, H. Vorbach, M. Huber, C. Armbruster. (C)ERS Journals Ltd 2001.

ABSTRACT: In contrast to uncomplicated juvenile laryngeal papillomas which may regress spontaneously, papillomatosis involving pulmonary parenchyma is associated with a poor outcome.

This report represents the case of a 34 yr-old female in whom respiratory papillomatosis resulted in voice problems and recurrent pneumonias due to bronchial obstruction. A computed tomographic scan of the chest showed worsening bilateral round cavitating consolidations. Bronchoscopy revealed polypoid lesions of the right vocal cord and the midtrachea which were confirmed as squamous papillomatosis by histology.

Interferon (IFN) $\alpha-2 b$ treatment was inefficient as was cidofovir monotherapy on a maintenance basis. Six months of IFN- $\alpha-2 b$ and cidofovir in combination led to a complete macroscopic disappearance of the laryngeal lesions and to an impressive regression of the tracheal papillomas and of the intrapulmonary consolidations.

These data provide support that severe respiratory papillomatosis can be safely treated by interferon $\alpha-2 b$ and cidofovir in combination. Probably the same mechanisms as in ribavirin plus interferon $\alpha-2 b$, in the treatment of patients with chronic hepatitis $C$, are responsible for the therapeutic success in this case.

Eur Respir J 2001; 17: 830-831.

\begin{abstract}
*Second and ${ }^{\#}$ First Medical Dept/ Pumologisches Zentrum, Institute for Pathology and Microbiology/Baumgartner Höhe and ${ }^{+}$First Surgical Dept/ Krankenanstalt Rudolfstiftung, Vienna, Austria.
\end{abstract}

Correspondence: C. Armbruster

Mantlegasse 23/2/12

A-1130 Vienna

Austria.

Fax: 4318775820

Keywords: Bronchoscopy cidofovir

interferon $\alpha-2 b$

respiratory system

squamous papillomatosis

Received: February 212000

Accepted after revision August 72000
Respiratory papillomatosis caused by human papillomavirus (HPV) is a rare but often severe disease. Benign epithelial proliferations may result in obstructions of the airways leading to chronic changes of the respiratory tract $[1,2]$. Treatment is generally based on surgical ablation of the lesions, usually using a carbon dioxide laser [2]. Intralesional application of cidofovir [(S)-1-(3-hydroxy-2-phosphonylmethoxypropyl) cytosine] was recently reported to be successful in laryngeal papillomatosis, but treatment of endobronchial and intrapulmonary lesions has not been studied [1-3].

\section{Case report}

A 34 yr-old woman was admitted to our hospital with respiratory papillomatosis in 1997. She had undergone more than two hundred microlaryngoscopies since she had been $7 \mathrm{yrs}$ old and suffered from voice problems and recurrent pneumonias due to bronchial obstruction. Interferon $\alpha-2 b$ treatment $\left(5 \times 10^{6}\right.$ units, three times a week) had been instituted at the age of 30 , but frequent recurrences remained to be a problem.

A computed tomographic scan of the chest showed bilateral round cavitating consolidations which worsened during the subsequent 18 months after admission (fig. 1). Bronchoscopy under generalized anesthesia was first performed in April 1997 and revealed polypoid lesions of the right vocal cord and the midtrachea. The histology of the tracheal and laryngeal biopsy specimens confirmed the diagnosis of squamous papillomatosis. HPV type 6 and 11 were demonstrated using
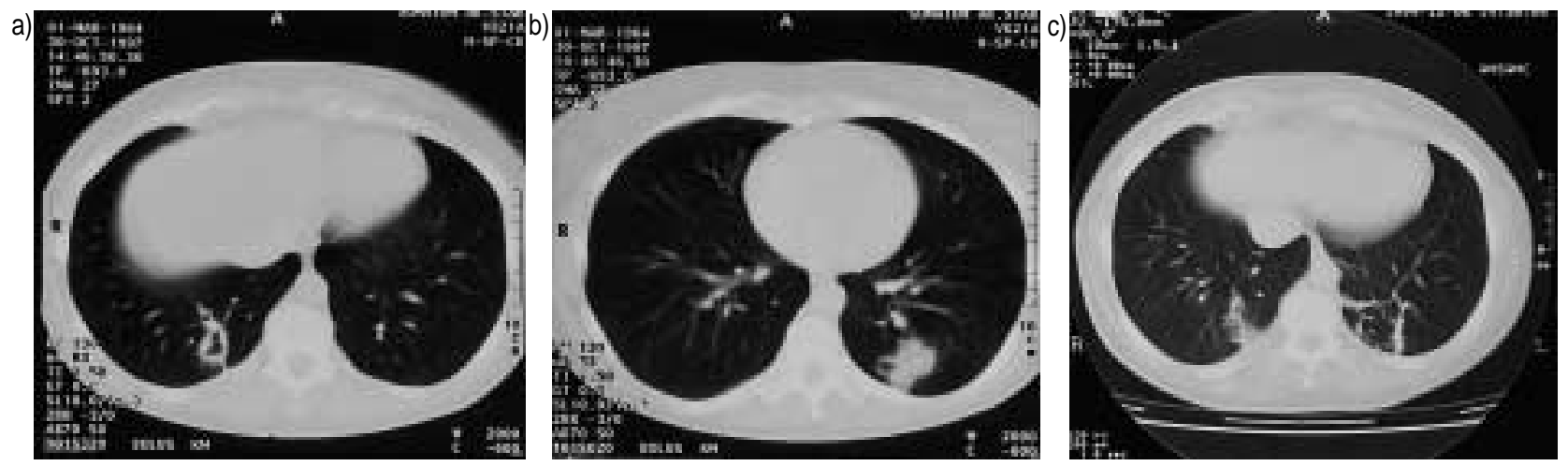

Fig. 1. - Computed tomographic scans of the chest. a, b) Bilateral round cavitating consolidations (October 1997); c) Marked response of the intrapulmonary consolidations due to cidofovir/interferon $\alpha-2 b$ combination therapy (December 1999). 
a)

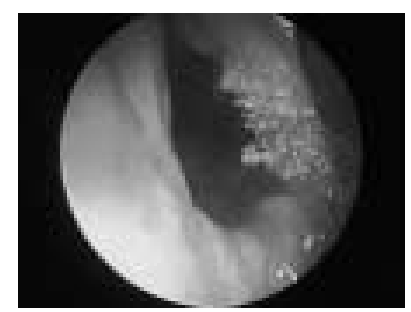

d)

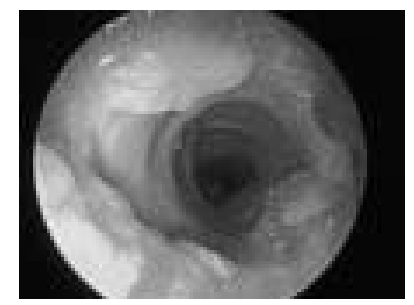

b)

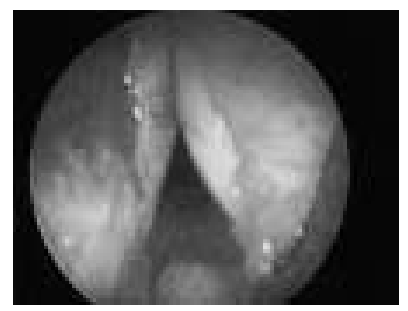

e)

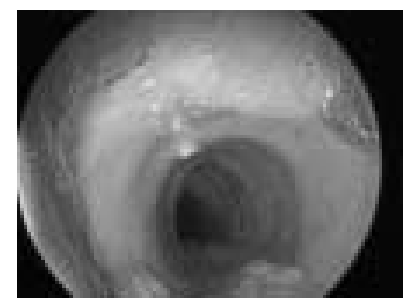

c)

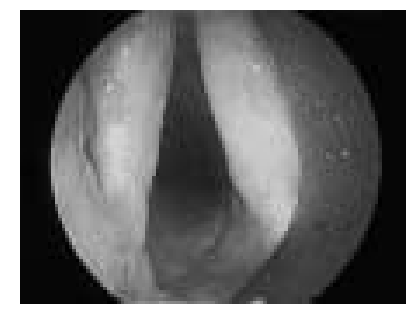

f)

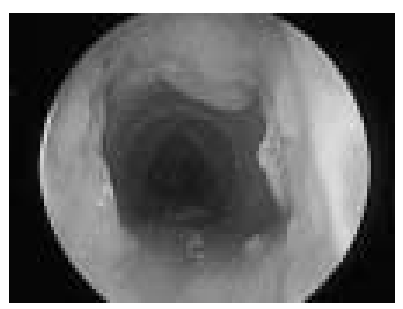

Fig. 2. - Regression of squamous papillomas of the larynx and the midtrachea following treatment. a) Laryngeal papillomas - the picture was taken during the second bronchoscopy (October 1998); b) Regression of laryngeal papillomas under cidofovir/ interferon $\alpha$-2b combination therapy; c) Complete macroscopic disappearance of laryngeal papillomas after 6 months of combination therapy; d) Circumferential polypoid tumour involving the trachea (October 1998); e) Marked response of the papillomas in the trachea after 6 months of cidofovir/interferon $\alpha$-2b combination therapy; f) Further regression of the papillomatous lesions involving the trachea.

polymerase chain reaction (Hybrid Capture II Test, Digene Corp., Beltsville, MD, USA).

Between 1997 and October 1998 the patient was treated with Argon laser vaporization twice. IFN- $\alpha-2 b$ treatment was continued until October 1998, when the patient was admitted again with large polypoid squamous papillomas of both vocal cords and a circumferential polypoid tumour involving the trachea (fig. 2). Based on these endoscopical findings IFN- $\alpha-2 b$ therapy was stopped due to lack of efficacy and cidofovir treatment was instituted (induction treatment: $5 \mathrm{mg} \cdot \mathrm{kg}^{-1}$ bodyweight once a week during two weeks, maintenance treatment: $5 \mathrm{mg} \cdot \mathrm{kg}^{-1}$ bodyweight every 2 weeks). Endoscopic control in December 1998 showed a regression of the laryngeal papillomas but there was evidence of progressing papillomatous lesions in the trachea (fig. 2).

Due to recurrence of papillomatosis in the larynx, IFN- $\alpha-2 b$ was added to cidofovir. Six months of this combination therapy led to a complete macroscopic disappearance of the laryngeal lesions and to a marked response of the papillomas in the trachea (fig. 2). A computed tomographic scan of the chest in December 1999 showed no evidence of endobronchial lesions and an impressive regression of the intrapulmonary consolidations (fig. 1).

At the given dose $\left(5 \mathrm{mg} \cdot \mathrm{kg}^{-1}\right.$ bodyweight every two weeks) cidofovir was well tolerated and no haematotoxicity, nephrotoxicity or hepatotoxicity could be detected during the 12-month treatment period.

\section{Discussion}

The course of respiratory papillomatosis is variable. In contrast to uncomplicated juvenile laryngeal papillomas which may regress spontaneously, papillomatosis involving pulmonary parenchyma is associated with a poor outcome [4]. The effect of intratumoural injections of cidofovir opens perspectives for HPV-induced lesions, which are easily accessible for injection therapy, but endobronchial and intrapulmonary lesions represent a therapeutic dilemma [1-3].

PRANSKY et al. [2] recently described a dramatic response of papillomatous lesions to intralesional cidofovir and IFN- $\alpha-2 \mathrm{a}$ in a child. To the best of the authors' knowledge, the efficacy of this treatment regimen in adult respiratory papillomatosis involving pulmonary parenchyma has not been reported at the time of our study.

The data presented herein provide support that combination therapy with cidofovir on a maintenance basis and interferon $\alpha-2 b$ is efficient in adult respiratory papillomatosis. It is possible that the same mechanisms involved in ribavirin plus interferon- $\alpha-2 b$ in the treatment of patients with chronic hepatitis $\mathrm{C}$ are responsible for the therapeutic success in our case [5].

\section{References}

1. Snoeck R, Wellens W, Desloovere C, et al. Treatment of severe laryngeal papillomatosis with intralesional injections of cidofovir ((S)-1-(3-hydroxy-2-phosphonylmethoxypropyl) cytosine). J Med Virol 1998; 54: 219 225.

2. Pransky SM, Margit AE, Kearns DB, Kang DR, Duncan NO. Intralesional cidofovir for recurrent respiratory papillomatosis in children. Arch Otolaryngol Head Neck Surg 1999; 125: 1143-1148.

3. Van Cutsem E, Snoeck R, Van Ranst M, et al. Successful treatment of a squamous papilloma of the hypopharynx-esophagus by local injections of (S)-1-(3hydroxy-2-phosphonylmethoxypropyl) cytosine. $J$ Med Virol 1995; 45: 230-235.

4. Williams SD, Jamieson DH, Prescott CA. Clinical and radiological features in three cases of pulmonary involvement from recurrent respiratory papillomatosis. Int J Pediatr Otorhinolaryngol 1994; 30: 71-77.

5. Barbaro G, Di Lorenzo G, Belloni G, et al. Interferon alpha-2B and ribavirin in combination for patients with chronic hepatitis $\mathrm{C}$ who failed to respond to, or relapsed after, interferon alpha therapy: a randomized trial. Am J Med 1999; 107: 112-118. 